\title{
Sonographic Evaluation of Shoulder Pathologies associated with Rotator Cuff Tear in Patients with Restricted Shoulder Movements
}

\author{
Sandeep Bendale ${ }^{1}$, Shashank Vedpathak ${ }^{2}$ \\ ${ }^{1}$ Assistant Professor, Department of Radiodiagnosis, ${ }^{2}$ Associate Professor, Department of Anatomy ${ }^{2}$, MIMER Medical College, \\ Talegaon Dabhade, Maharashtra, India
}

Corresponding author: Dr Shashank Vedpathak, Department of Anatomy, MIMER Medical College, Talegaon Dabhade, Maharashtra, India

DOI: http://dx.doi.org/10.21276/ijcmsr.2019.4.4.13

How to cite this article: Sandeep Bendale, Shashank Vedpathak. Sonographic evaluation of shoulder pathologies associated with rotator cuff tear in patients with restricted shoulder movements . International Journal of Contemporary Medicine Surgery and Radiology. 2019;4(4):D54-D57.

\section{A B S T R A C T}

Introduction: Ultrasonography is an easily accessible diagnostic tool for evaluating shoulder pathologies. Study aimed at sonographic evaluation of non rotator cuff findings associated with rotator cuff tear in patients with restricted movements of shoulder.

Material and Methods: This was a prospective study of 50 patients with restricted movements of shoulder who underwent shoulder sonography in Dept of Radiodiagnosis of our hospital with GE systems - LOGIQ 3 USG machine. Patients with rotator cuff tear were identified and other shoulder pathologies if any associated with them were identified and recorded. Results: Our study found that calcification of rotator cuff tendons, acromioclavicular joint osteoarthritis, peribicipital tendon fluid, Subacromial Subdeltoid bursal fluid were some of the pathologies associated with tear of rotator cuff tendons and they increased the positive predictive value for diagnosing rotator cuff tear by USG.

Conclusion: Our study has found that in patients with restricted movements of shoulder; screening of affected shoulder for the nonrotator cuff disorders improves the diagnostic accuracy in detecting rotator cuff tear with USG.

Keywords: Acromioclavicular Joint Osteoarthritis, Bursal fluid, Calcificific Tendinosis, Peribicipital Tendon Fluid, Supraspinatus,

\section{INTRODUCTION}

Shoulder joint is a multiaxial joint formed by head of humerus and glenoid cavity of scapula. Head of humerus is much larger than glenoid cavity. Small and shallow glenoid cavity permits greater range of mobility sacrificing stability. Overlying the glenohumeral joint, there is a secondary socket formed by coracoid and acromian processes and coracoacromial ligament connecting them; the coracoacromial arch. It is separated from tendon of supraspinatus by subacromial bursa. During overhead shoulder movement, greater tubercle of humerus impinges on acromian process and halts the movement. Lateral rotation of humeral head allows it to slip beneath the coracoacromial arch allowing the further movement.

Humeral head cannot pass beneath acromion whenever there is swelling of supraspinatus or other rotator cuff tendon due to tendinopathy or tendon degeneration, tenosynovitis or bursitis. This may lead to impingement of humeral head beneath acromion. Tendon degeneration or other pathologies may occur due to chronic excessive use of shoulder as in sports related injuries. As supraspinatus is more prone to be trapped between humerus and acromion; it is the most commonly involved tendon among the rotator cuff. Pain may be caused by involvement of subacromial bursa or tendon of supraspinatus itself.

Eventually, one of the common findings in patients with pain and restriction of movements in shoulder is rupture of supraspinatus tendon. Other rotator cuff tendons may also get involved. These Rotator cuff pathologies are classified as tendinopathy, partial and full thickness rupture in increasing order of severity.

High resolution ultrasound is easily available, cost effective, nonionising modality with a sensitivity of $86 \%$ and specificity of $91 \%$ in detecting rotator cuff disorders. ${ }^{1}$ The fatty infiltration and muscle atrophy are also well depicted on sonography.

Ultrasonography can also differentiate nonrotator cuff disorders like subacromial and subdeltoid bursitis, tenosynovitis, tendinosis etc which clinically resemble like rotator cuff tear.

In this observational study, we have focused on these nonrotator cuff sonographic findings which are seen to be associated with rotator cuff tendon tear primarily supraspinatus.

\section{MATERIAL AND METHODS}

This prospective, hospital based study of "Sonographic evaluation of shoulder pathologies associated with rotator 
cuff tear in patients with restricted shoulder movements" was carried in Department of Radiodiagnosis of B.J. Medical College and Sasoon General Hospital. Ethical committee approval was taken prior to beginning of the study and consent was taken from patients who were willing to be part of the study. The study included 50 patients with restricted movements of shoulder attending the orthopaedic OPD of our hospital who were referred to the Department of Radiodiagnosis for USG of Shoulder. Detail clinical history of patients is recorded. Patients were subjected to ultrasound examination with high frequency transducer. Findings of ultrasound examination were recorded.

Patients underwent MRI as per orthopaedic advice for further management.

\section{Selection of patient}

Inclusion criteria:

1) Patients with restricted movements of shoulder were included in the study.

2) Fifty such patients were subjected to high resolution ultrasound examination with GE systems - LOGIQ 3 USG machine using high frequency transducer.

\section{Exclusion criteria:}

1) Patients with recent trauma causing restriction of movement were excluded from the study.

2) All patients who did not consent to be a part of the study.

Patient preparation: No specific patient preparation was needed.

\section{RESULTS}

The present study included 50 patients with restriction of shoulder movements. Patients with rotator cuff disease were evaluated for other associated pathologies by USG. We recorded partial or full thickness rotator cuff tear. Along with it we also observed nonrotator cuff USG findings in these patients which include calcifications of rotator cuff tendons, fluid around bicep tendon, osteoarthritis of acromioclavicular joint and fluid in subacromial subdeltoid bursa. These observations in our study were tabulated and their incidence was found out.

The diagnosis of rotator cuff tear was later confirmed by MRI examination.

Age distribution of patients: Table number 1 shows that, almost half patients were in the age group of 51-60 yrs (44\%) while 26\% patients were in age group 61-70 years (Table-1).

Gender distribution of cases: Table number 2 shows that, Incidence of shoulder pathologies associated with rotator cuff tear was slightly more in male patients (56\%) than their female counterparts (44\%) (Table-2).

Incidence of patients with rotator cuff tear: Table number 3 shows, partial thickness tear was seen in 21 patients and full thickness tear was seen 10 patients out of 50 . So overall $62 \%$ patients showed tear of rotator cuff tendons (Table-3).

USG findings: Calcifications: According to table no. 4, Out of 50 patients 5 patients had supraspinatus calcific tendinitis and 1 patient had infraspinatus calcific tendinitis (Table-4).

\begin{tabular}{|l|c|c|c|}
\hline \multirow{2}{*}{ Age in Yrs } & \multicolumn{2}{|c|}{ Number of patients } & \multirow{2}{*}{ Total (\%) } \\
\cline { 2 - 3 } & Male & Female & \\
\hline $41-50$ & 4 & 6 & $10(20 \%)$ \\
\hline $51-60$ & 13 & 9 & $22(44 \%)$ \\
\hline $61-70$ & 8 & 5 & $13(26 \%)$ \\
\hline$>70$ & 3 & 2 & $5(10 \%)$ \\
\hline Total & 28 & 22 & 50 \\
\hline \multicolumn{4}{|c|}{ Table-1: Age distribution of patients } \\
\hline
\end{tabular}

\begin{tabular}{|l|c|c|}
\hline Sex & No. of cases & Percentage \\
\hline Male & 28 & $56 \%$ \\
\hline Female & 22 & $44 \%$ \\
\hline Total & 50 & $100 \%$ \\
\hline \multicolumn{2}{|c|}{ Table-2: Gender distribution of cases } \\
\hline
\end{tabular}

\begin{tabular}{|l|c|c|}
\hline Condition & $\begin{array}{c}\text { Number } \\
\text { of } \\
\text { patients }\end{array}$ & Percentage \\
\hline Partial thickness rotator cuff tears & 21 & $42 \%$ \\
\hline Full thickness rotator cuff tears & 10 & $20 \%$ \\
\hline \multicolumn{2}{|c|}{ Table-3: Incidence of patients with rotator cuff tear } \\
\hline
\end{tabular}

\begin{tabular}{|c|c|c|c|}
\hline Condition & Criteria & No of patient & Percentage \\
\hline \multirow[t]{2}{*}{ Supra Spinatus } & Present & 5 & 10 \\
\hline & Absent & 45 & 90 \\
\hline \multirow[t]{2}{*}{ Infraspinatus } & Present & 1 & 2 \\
\hline & Absent & 49 & 98 \\
\hline \multirow[t]{2}{*}{ Subscapularis } & Present & 0 & 0 \\
\hline & Absent & 50 & 100 \\
\hline \multirow[t]{2}{*}{ Teres Minor } & Present & 0 & 0 \\
\hline & Absent & 50 & 100 \\
\hline \multirow[t]{2}{*}{ Biceps tendon } & Present & 0 & 0 \\
\hline & Absent & 50 & 100 \\
\hline
\end{tabular}

\begin{tabular}{|l|l|c|c|}
\hline & Criteria & $\begin{array}{c}\text { Number } \\
\text { of } \\
\text { Patients }\end{array}$ & Percentage \\
\hline $\begin{array}{l}\text { Acromio-clavicular joint } \\
\text { Osteoarthritis }\end{array}$ & Present & 16 & 32 \\
\cline { 2 - 4 } & Absent & 34 & 68 \\
\hline \multicolumn{2}{|c|}{ Table-5: USG findings: Acromioclavicular joint osteoarthritis } \\
\hline
\end{tabular}

\begin{tabular}{|l|l|l|l|}
\hline & Criteria & $\begin{array}{l}\text { No of } \\
\text { patient }\end{array}$ & Percentage \\
\hline Peribicipital tendon Fluid & Present & 21 & 42 \\
\cline { 2 - 4 } & Absent & 29 & 58 \\
\hline
\end{tabular}

Table-6: USG findings: Peribicipital tendon fluid.

\begin{tabular}{|l|l|c|c|}
\hline & Criteria & $\begin{array}{c}\text { No of } \\
\text { patient }\end{array}$ & Percentage \\
\hline \multirow{2}{*}{$\begin{array}{l}\text { Subacromial-subdeltoid busal } \\
\text { fluid }\end{array}$} & Present & 12 & 24 \\
\cline { 2 - 4 } & Absent & 38 & 76 \\
\hline \multicolumn{4}{|c|}{ Table-7: USG findings: Bursal fluid } \\
\hline
\end{tabular}




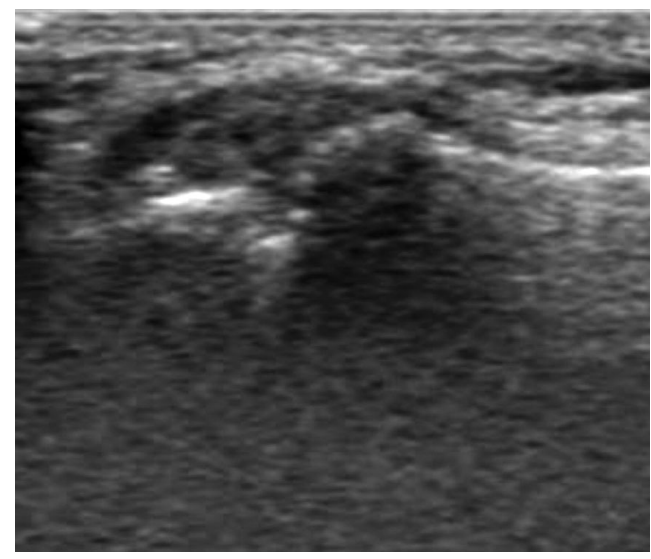

Figure-1: AC joint osteoarthritis:

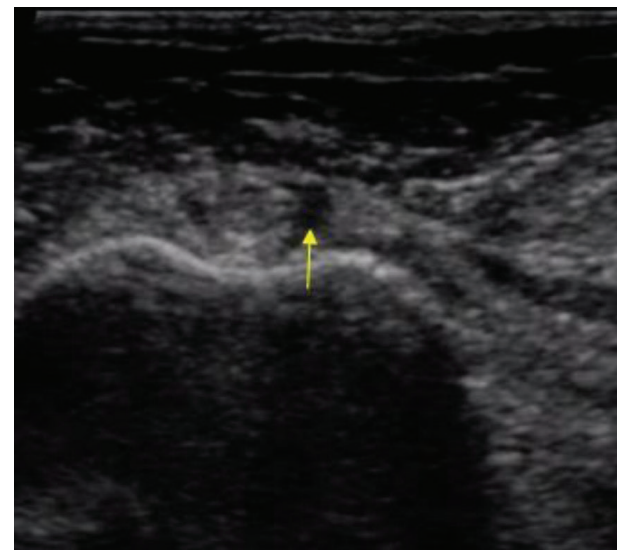

Figure-2: Peribiccipital tendon fluid- trans

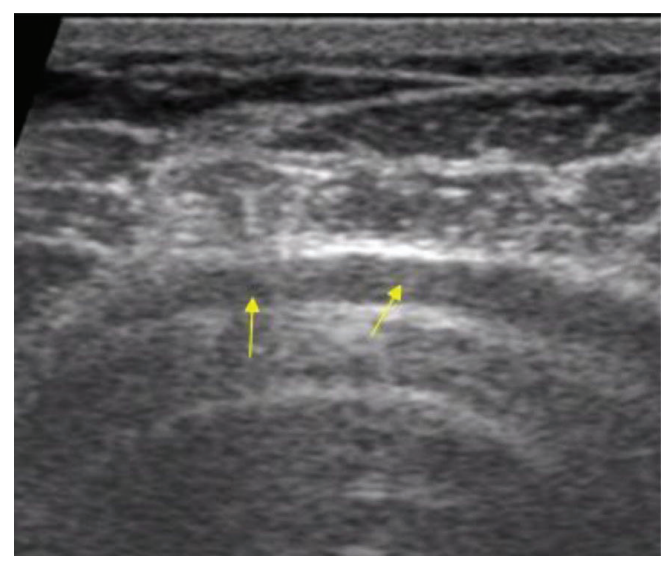

Figure-3: Subdeltoid bursal effusion

USG findings: Acromioclavicular joint osteoarthritis: Table number 5 shows, degenerative changes in AC joint in 16 patients on USG. These patients also had partial thickness supraspinatus tears (Table-5).

USG findings: Peribicipital tendon fluid: Table number 6 shows $42 \%$ patients had peribicipital tendon fluid (Table-6).

USG findings: Bursal fluid: Table number 7 shows 24\% patients with restricted shoulder movements had subdeltoid bursal fluid.

\section{DISCUSSION}

The present study was undertaken to find out different causes of shoulder pathology including rotator cuff disease and nonrotator cuff USG findings associated with them in patients of restricted movements of shoulder.

Patients included in our study were referred for restricted movements and shoulder pain. All 50 patients underwent USG of both shoulders. The findings of rotator cuff disease and other associated findings were recorded and tabulated.

\section{Age distribution of patients}

Our study found that incidence of degenerative shoulder diseases - including rotator cuff tear goes on increasing as age advances. Willliam D. Middleton et $\mathrm{al}^{2}$ in their study have found similar results.

\section{Gender distribution of cases}

Our study found slightly more male predominance in shoulder pathologies. These findings correlate with the study conducted by Thomas D. Brandt ${ }^{3}$ on shoulder pathologies by sonography.

\section{Incidence of patients with rotator cuff tear}

Our study showed, $62 \%$ of patients with restricted shoulder movements had rotator cuff tears. Kumugai, H. Ito and et $\mathrm{al}^{4}$ found full thickness rotator cuff tear in 12 patients and partial thickness tear in 7 patients out of 42 patients studied. Vlychou $\mathrm{M}$ et $\mathrm{al}^{5}$ found partial thickness tear in 44 patients out of 56 cases studied

\section{USG findings: calcifications of rotator cuff tendons}

Ultrasonography is sensitive at demonstrating focal calcium hydroxyapatite deposition within the rotator cuff tendons. This accumulation most commonly occurs within the supraspinatus tendon near the greater tuberosity insertion but may be seen in other cuff tendons.

Calcification can be identified as focal areas of increased reflectivity with posterior acoustic shadowing. Jose Luis et $\mathrm{al}^{6}$ found rotator cuff calcific tendinosis was associated with significant shoulder pain and restricted movements.

In our study, 5 Patients who showed supraspinatus calcification, had partial supraspinatus tears. These patients were of age more than 60 years which is fairly suggesting that degenerative calcific changes are more common in eldelrly patients.

\section{USG findings: Acromioclavicular joint osteoarthritis.}

Acromioclavicular joint is fibrocartilagenous joint that is known to undergo degenerative changes beginning as early as fourth decade. The capsular hypertrophy and joint effusion is noted in degenerative joint disease. Carretta $G$ and et $\mathrm{al}^{7}$ studied 175 patients with shoulder pain and found AC joint pathology in $105(60 \%)$ and rotator cuff tear in $63 \%$. They conclude that acromioclavicular joint screening is valuable during shoulder ultrasound studies. Alasarela, E Tervonen, and et $\mathrm{al}^{8}$ prospectively studied 63 patients of age group 45 to 64 and concluded that in $\mathrm{AC}$ joint the mean ultrasonographic distance of the joint capsule from the bone rim was $2.9 \mathrm{~mm}+/$ - standard deviation (SD) $0.5 \mathrm{~mm}$ in 40 to 80 year age control group.

When the ultrasonographic distance of the joint capsule from the bone rim was $<3 \mathrm{~mm}$, there is usually no synovial hypertrophy or effusion in acromioclavicular joint. We scanned AC joint in two planes- transverse and longitudinal plane and found degenerative changes in $32 \%$ patients on 
USG. So, acromioclavicular joint pathologies should be screened in patients with shoulder movement restriction (Fig-1).

\section{USG findings: Peribicipital tendon fluid}

Biceps tendon is present anteriorly. We used bicipital groove as an anatomical landmark to differentiate subscapularis tendon from supraspinatus tendon (fig-2).

Subscapularis lies medial to this bicipital groove. Long head of biceps tendon is scanned in this groove. Pressure from the transducer can displace fluid, and a careful search for fluid was made in every patient with this in mind. We noted 21 patients with peribicipital tendon fluid. The peribicipital tendon fluid finding was confirmed in both transverse and longitudinal images. Transverse images appear better in showing oval tendon surrounded by hypoechoeic fluid in concave bicipital groove. All these patients were having partial of full thickness rotator cuff tear. Mary S. Hollister et $\mathrm{al}^{9}$ has suggested that fluid in peribicipital tendon region is having high predictive value for rotator cuff tears.

\section{USG findings: Subacromial-subdeltoid bursal fluid}

Subacromial-subdeltoid bursa is seen under deltoid. Deep to it lie rotator cuff tendons. Normally this bursa is just recognizable as thin hypoechoeic layer between deltoid and rotator cuff tendons (fig-3).

It is seen associated with both full and partial thickness tears of supraspinatus. Fluid is anechoeic which differs from hypoechoeic bursal wall. Synovial thickening also appear hypoechoic which is seen in chronic impingement syndromes. Pressure applied by ultrasonography probe is also helpful in differentiating this bursal fluid collection and synovial thickening, where bursal fluid will be emptied by compression, while synovial thickening alters little. We found Subacromial-subdeltoid fluid in 12 patients. 6 of these patients had partial thickness tear and 6 had full thickness tears on USG. Mary S. Hollister et $\mathrm{al}^{9}$ in their study of 163 patients undergoing operative procedure for shoulder pathology found subacromial subdeltoid bursal fluid in $22 \%$ patients. Marnix van Holsbeeck et a ${ }^{10}$ illustrated the findings in subacromial subdeltoid bursal distension in 63 normal shoulders.

The findings of fluid in the peribicipital region and Subacromial- subdeltoid bursa especially when combined with the glenohumeral joint effusion is highly specific and has high positive predictive value for associated rotator cuff tears. Carlo martinoli et $\mathrm{al}^{11}$ has advocated wider use of USG in evaluation nonrotator cuff disorders as it is quick, noninvasive and cost effective modality which is capable of examining tissues in both dynamic and static states.

\section{CONCLUSION}

Our study has found that rotator cuff tear is the most common reason for restriction of movements in patients with shoulder pathology. This tear is most common in supraspinatus tendon, is more common in the elderly, and is slightly more common in males as compared to females. Our study has also found that along with rotator cuff tear many other disorders related with shoulder may be present which can be sonographically diagnosed and should not be missed during shoulder ultrasound. These include calcific tendinosis of rotator cuff, acromioclavicular joint osteoarthritis, peribicipital tendon fluid and subacromial subdeltoid bursal fluid.

\section{REFERENCES}

1. Floris I van Mopes, Onmo Veldkampb, Jan Roordab. Role of ultrasonography in evaluation of painful shoulder, Eur Jr of Radiology 1995; 19(2):142-146.

2. William D. Middleton, Gerald Eldstein, William R.Remus, G. Leland Melson, William G. Totty, William A. Murphy. Sonographic Detection of rotator cuff tears. AJR 1985; 144(3):349-353.

3. Brandt TD, Cardone BW, Grant TH, et al, rotator cuff sonography: reassessment radiology. 1989; 173(2): 323327.

4. Kumagai H Ito and Kubo A. Sonographic findings of rotator cuff tears: correlation with MR imaging Nippon Igaku Hoshsen Gakkai Zasshi 1994; 54(6): 459-464.

5. Vlychou M, Dailiana Z, Fotiadou A, Papanagitou M, Fezoulidis IV, Malizos K Symptomatic Partial Rotator Cuff Tears: Diagnostic Performance of Ultrasound and Magnetic Resonance Imaging with Surgical Correlation. Acta Radiol. 2009; 50(1): 101-105.

6. Jose Luis del Cura, Inaki Torre, Rosa Zabla, Ana Legorburu. Sonographically Guided Percutaneous Needle Lavage in Calcific Tendinitis of Shoulder. Short and Long Term Results. AJR 2007; 189(3): 128-134.

7. Carretta G, De Nicola T, Gongolo R, Liberati L, Villabruna M. (1994), Ultrasonography of the shoulder: the acromioclavicular joint. Radiol Med. 1994; 88(1-2): 1-7.

8. Alasarela, E Tervonen, O Takalo, R Lahde, S Suramo, Acromioclavicular joint osteoarthritis (1997 Oct) The Journal of rheumatology, University of Oulu.

9. Hollister MS, Mack LA, Patten RM et al: Association of sonographically detected subacromial/ subdeltoid bursal effusion and intra-articular fluid with rotator cuff tear. AJR Am J Roentgenol 1995; 165(3): 605-608.

10. Van Holsnbeeck MT Kolowich PA Eyler WR et al US depiction of partial thickness tear of the rotator cuff Radiology 1995; 197(6): 443-446.

11. Carlo Martinoli, Stefani Binachi, Nocolo Prato et al. US of the Shoulder: Non-Rotator Cuff Disorders. Radiographics 2003; 23(1): 381-401.

Source of Support: Nil; Conflict of Interest: None

Submitted: 18-09-2019; Accepted: 15-10-2019; Published online: 05-11-2019 